\title{
Quality and Certification of Electronic Health Records
}

\section{An overview of current approaches from the US and Europe}

\author{
A. Hoerbst'; E. Ammenwerth ${ }^{2}$ \\ ${ }^{1}$ Research Division eHealth and Telemedicine, UMIT - University for Health Sciences, Medical Informatics and Technology, Eduard- \\ Wallnoefer-Zentrum 1, Hall in Tirol, Austria; ${ }^{2}$ Institute for Health Information Systems, UMIT - University for Health Sciences, \\ Medical Informatics and Technology, Eduard-Wallnoefer-Zentrum 1, Hall in Tirol, Austria
}

\section{Keywords \\ Quality, certification, electronic health record, medical records}

\section{Summary}

Background: Numerous projects, initiatives, and programs are dedicated to the development of Electronic Health Records (EHR) worldwide. Increasingly more of these plans have recently been brought from a scientific environment to real life applications. In this context, quality is a crucial factor with regard to the acceptance and utility of Electronic Health Records. However, the dissemination of the existing quality approaches is often rather limited.

Objectives: The present paper aims at the description and comparison of the current major quality certification approaches to EHRs.

Methods: A literature analysis was carried out in order to identify the relevant publications with regard to EHR quality certification. PubMed, ACM Digital Library, IEEExplore, CiteSeer, and Google (Scholar) were used to collect relevant sources. The documents that were obtained were analyzed using techniques of qualitative content analysis.

Results: The analysis discusses and compares the quality approaches of CCHIT, EuroRec, IHE, openEHR, and EN13606. These approaches differ with regard to their focus, support of service-oriented EHRs, process of (re-)certification and testing, number of systems certified and tested, supporting organizations, and regional relevance.

Discussion: The analyzed approaches show differences with regard to their structure and processes. System vendors can exploit these approaches in order to improve and certify their information systems. Health care organizations can use these approaches to support selection processes or to assess the quality of their own information systems.

\section{Correspondence to:}

Dr. Alexander Hoerbst

Research Division eHealth and Telemedicine

UMIT - University for Health Sciences, Medical Informatics

and Technology

Eduard-Wallnoefer-Zentrum 1

6060 Hall in Tirol/Austria

Email: alexander.hoerbst@umit.at

http://ehealth.umit.at

Tel.: +435086483814

Fax: +43508648673814

\section{Appl Clin Inf 20010; 1: 149-164}

doi: $10.4338 / \mathrm{ACl}-2010-02-\mathrm{R}-0009$

received: January 17, 2010

accepted: April 21, 2010

published: May 19, 2010
Citation: Hoerbst A, Ammenwerth E. Quality and certification of electronic health records - An overview of current approaches from the US and Europe. Appl Clin Inf 2010; 1: 149-164

http://dx.doi.org/10.4338/ACI-2010-02-R-0009 


\section{Background}

Healthcare is facing an unprecedented number of patients worldwide. This increase in patients comes along with a permanent increase of techniques and medical knowledge that are available for diagnosis and treatment, in turn resulting in e.g. higher costs and the need for a close collaboration between various health professionals [1] as healthcare becomes increasingly more specialized. According to Eurostat, healthcare expenses have increased from $€ 4,889$ in 2003 to $€ 5,658$ in 2006 per capita in the USA, which is an increase of $16 \%$. Austria is facing a similar situation, in which healthcare expenses increased by $11 \%$ from $€ 2,832$ in 2003 to $€ 3,146$ in 2006 [2]. Such a development puts high pressure on healthcare systems, as there is a need to keep costs low in order to stay financially feasible while guaranteeing a constant, or even increasing, level of quality. To achieve such an ambitious goal there is, among other things, the need for information systems that foster the collaboration of various health professionals, integrate the patient in his/her medical treatment, and support a high level of quality along the process of patient treatment.

The concept of an Electronic Health Record (EHR) sets out to support these requirements by closing the gap between institution-specific patient data and a comprehensive, longitudinal collection of a patient's health and healthcare data [3] that supports information exchange between various healthcare providers. Within the concept of an EHR, the patient is regarded as a partner who actively participates in his/her treatment by accessing, adding, and managing health-related data, thereby supporting the quality of care $[4,5]$. The concept of an EHR where a patient is actively involved is also called a Personal Health Record (PHR) in referring to Waegemann [6].

\subsection{Quality of Electronic Health Records}

The recent past with regard to Electronic Health Records (EHR) is more and more characterized by the actual implementation of EHRs in real-life clinical environments. Concepts which have so far been limited to a virtually scientific environment have reached a degree of maturity to overcome the prototype stage and become integrated in daily routine. Particularly Scandinavian countries are on the cusp of realizing EHRs or at least parts of them (see e.g. [7, 8]). Apart from the successful selection and implementation of a certain EHR concept for a given environment, overall success of such a project is dependent on a number of additional requirements which cannot directly be related to software engineering. These requirements are subject to great variance, depending on a number of country- or region-specific parameters such as legislation, norms, different strength of stakeholders or organizational limits.

The definition of data access rights, as an example, is a major point of controversy and an inhibitor in the process of the implementation of an Electronic Health Record in Austria or Germany, whereas in Denmark this was principally a minor concern [9].

This leads to the problem of the establishment of a common view of EHR quality. The concept of quality is often defined as the degree to which a set of inherent characteristics fulfills requirements [10]. This definition focuses on a mere technocratic perspective of quality and does not account for quality as a whole. The actual definition and characterization of the quality of EHRs marks a more significant problem, as the large heterogeneity in requirements or tacit knowledge makes it difficult to define a consolidated set of characteristics that have to be fulfilled. In talking about software quality in particular, the definition of functional software requirements is highly dependent on national preferences.

\section{Objectives}

The actual implementation of EHRs in the healthcare sector is a rather new development. Accordingly, there have not been many initiatives so far that deal with EHRs with regard to quality. Furthermore, most of the existing approaches imply a traditional view on quality, in general, and software quality, and they do not consider EHR specific characteristics. 
The present paper aims at the description of the current major quality certification approaches or those approaches that foster quality in the field of EHRs and then contrasts them. The selection of approaches is, geographically, not restricted.

\section{Methods}

The results that are described in the present paper were gathered as a part of an extensive research project that started in 2007 and ended in 2009 with the aim to support the transnational quality certification of EHR services. The literature analysis that was carried out during the project - which is the basis for this manuscript - aimed at finding relevant publications with regard to the quality certification of Electronic Health Records, whereas the term Electronic Health Records was used in a broader sense that also included Electronic Medical Records, Personal Health Records, and Patient Health Records. In the context of the project, certification was defined according to the EN 45011 as a means carried out by a neutral third party to demonstrate that a product is in accordance with a norm or other normative document. In addition all initially retrieved results during the project period were updated by the end of 2009 to guarantee that recent developments are covered by the manuscript.

\subsection{Data Collection}

PubMed, ACM Digital Library, IEEExplore, CiteSeer, and Google (Scholar) were used to collect relevant documents regarding the quality and certification of EHRs. The initial list of keywords was obtained by selecting relevant MeSh-Terms. The analysis of the documents that were gathered through these terms yielded additional keywords and references to additional document sources. The following keywords or combinations were used: software, quality, certification, Electronic/Personal Medical/Health Record, EHR Standards, EHR certification, and EHR quality. The search was terminated by using the concept of theoretical saturation. Out of the references found by using the aforementioned keywords a total of 136 documents were selected according to their title and were then analyzed in greater detail. The following basic ex-/inclusion criteria were used for the primary selection: The title contains a combination of the keywords used for the search. The title indirectly refers to the quality of EHRs by containing one keyword and combining it with another term that can be related to quality (certification) of EHRs such as best practice, experiences, evaluation etc.

\subsection{Data Analysis}

The documents that were retrieved by the first selection were analyzed by two reviewers. In the first step, the documents were roughly judged regarding their quality and content. This was carried out by prioritizing documents (peer-reviewed journals, peer-reviewed conferences, journals, etc.) and by analyzing abstracts with regard to the keywords contained and the matching of the definition of certification (see chapter 3. Methods) and quality (see chapter 1. Background). The following basic criteria where used for ex-/inclusion with regard to content of the documents: The source refers to a widely accepted approach to certify, evaluate or foster quality of EHRs. The source describes experiences with such an approach. The source does not refer to an approach (accepted or not) that is limited to a specific part of an EHR e.g. medication.

Based on this judgment, the reviewers discussed their results thereafter in order to match all of the discrepancies in the selection that occurred. The selected documents were analyzed in detail using the following criteria to identify and describe certification approaches: Name, structure and organization of the approach, certification and testing processes, origin and relevance. 


\section{Approaches that support or certify the Quality of EHRs}

The following paragraphs aim at the description of selected, major organizations and their approaches that support the quality and/or certification of Electronic Health Records. The consideration of what is regarded as an approach that supports quality, or even certifies quality, that is generally difficult and to some extent it is always subjective, depending on the way and extent to what quality is defined. Therefore, this section does not claim to be complete. Furthermore, the number of publicly available, comprehensive, and EHR specific approaches that are known to the authors is rather limited.

This chapter starts by introducing the Certification Commission for Healthcare Information Technology (CCHIT) and its approach, which is primarily relevant for the United States. Including a description of the CCHIT certification, the existing cooperations and additional projects and the implications of the American Recovery and Reinvestment Act on the CCHIT.

These explanations are followed by introducing its European equivalent EuroRec, which is focused on the European market. EuroRec is also described with regard to its certification and existing cooperations and additional projects.

Apart from actual certification approaches, this chapter is also dedicated to the introduction of quality-supporting approaches, includingthe IHE, openEHR, and EN13606.

\subsection{The US: Certification Commission for Healthcare Information Technology (CCHIT)}

The CCHIT [11] was founded in 2004 as a Non-profit organization and is financed by industry partners. Among the founding partners are the American Health Information Management Association (AHIMA), the Healthcare Information and Management Systems Society (HIMSS), and the National Alliance for Health Information Technology (Alliance). Meanwhile, other partners have joined the CCHIT, such as the American Academy of Pediatrics (AAP) and the American College of Physicians (ACP).

The function of the CCHIT is to establish efficient, trustworthy, and sustainable mechanisms for the certification of applications within healthcare to increase the robustness and interoperability of these applications [12]. With regard to its function, the CCHIT was commissioned by the U.S. Department of Health and Human Services (HHS) in 2005 with the establishment of quality criteria and a certification process for EHRs. The process of development was not only targeted towards the establishment of a set of criteria and the corresponding certification processes but also to influence the harmonization process of different standards. Therefore, CCHIT closely cooperated with different standardization organizations.

\subsubsection{CCHIT Certification}

The certification that is offered by CCHIT has evolved over time. Whereas, at the beginning, only certification for inpatient and ambulatory EHRs was offered, they now offer additional certification for emergency department EHRs, ePrescribing, and Health Information Exchange. The certification primarily covers functionality, security, and interoperability, and is hierarchically structured in criteria and sub-criteria. Neither the structure nor the requirements themselves are based on a formal model or representation in the CCHIT approach. The criteria are primarily derived from existing standards. Approximately $70 \%$ of all the requirements deal with functionalities [13]. $>$ Table 1 shows some examples for different functional criteria. System vendors are provided with a certification handbook and test-scripts for self-evaluation.

The process of developing requirements, designing certifications, and inspection processes is performed by Working Groups within the CCHIT [14]. Currently, the CCHIT operates 16 working groups that deal with domain specific topics, such as cardiovascular health or child health as well as more generic topics, e.g. privacy and security. Working groups consist of volunteer members who are chosen by CCHIT based on their individual expertise and experience within a certain field. Whenever working groups change or improve the existing processes or certifications, the results undergo a period of public comment [14] where anyone may comment on the changes and im- 
provements. Comments are considered by the responsible working groups and are answered by grouped comments that are published on the CCHIT website.

The actual certification is carried out by three CCHIT auditors. The certification is then valid for a period of three years and has to be renewed after three years or if the system undergoes major changes within those three years. The initial certification costs for the year 2011 are an average of $\$ 41,000$ [15]. By the end of 2009 there were approximately 210 systems certified by the CCHIT, of which 186 are ambulatory EHR systems.

\subsubsection{CCHIT Cooperation and additional Projects}

The CCHIT is permanently enhancing their certification as well as their processes by cooperating with different organizations. Since 2005, the CCHIT together with the National Committee for Quality Assurance (NCQA) [16] has developed an EHR certification with regard to the compliance and compatibility of EHRs to the requirements that are defined by the American Diabetes Association (ADA). This mainly includes the requirements defined by the Diabetes Physician Recognition Program with regard to data collection and reporting. CCHIT also cooperates with Mitre Inc. to develop a tool to check the compliance of EHR products and data networks with CCHIT requirements. The project is called LAIKA and should allow vendors to test and verify their products based on an open source software testing framework prior to CCHIT certification [17].

\subsubsection{CCHIT and the American Recovery and Reinvestment Act 2009}

In February 2009, the American Recovery and Reinvestment Act (ARRA) [18] was passed, which is a comprehensive economic stimulus package initiated by the President of the United States to stabilize the U.S. economy during and after the economic turndown. The act covers several domains, among them healthcare, with an allocated budget of $\$ 147.7$ billion. Within this budget, an estimated more than $\$ 32$ billion according to the U.S. Congressional Budget Office are available for incentives to healthcare providers for the adoption and meaningful use of certified EHRs within the next 10 years. The Health IT Policy Committee [19] has so far elaborated a proposal for the criteria of the meaningful use in the context of EHRs and published these criteria [20] in its transmittal letter to the national coordinator for health IT on July 16, 2009. The Health IT Standards Committee [19] has meanwhile concretized the criteria [21] for meaningful use and has also identified the potential security and privacy standards [22] that conform to the ARRA requirements. Both documents have been submitted to the national coordinator for health IT on August 20, 2009 for a decision.

CCHIT has recently announced that they will apply to be accredited as an official certification body for the ARRA certification of EHR systems. CCHIT has already started a preliminary program [23] that aims at the certification of an EHR system with regard to the ARRA requirements. The certification program that has been developed so far is very general and reflects a subset of the already existing CCHIT certifications.

\subsection{Europe - European Institute for Health Records (EuroRec)}

The EuroRec Institute [24] is a Non-profit umbrella organization that is based on a Network of nationally organized, independent ProRec Centers and was founded in 2003. Apart from their organizational independence, all ProRec-Centers share the same goals and rely on the same fundamental principles. At the end of 2009, fifteen national ProRec-Centers (Austria, Belgium, Bulgaria, Denmark, France, Italy, Germany, Ireland, Romania, Slovenia, Spain, Slovakia, Serbia, The Netherlands, and the United Kingdom) have already been established and an additional seven (Norway, Cyprus, Greece, Hungary, Portugal, Poland, and Sweden) are currently applying to be accredited by EuroRec.

The aim of EuroRec and the affiliated ProRec Centers is to foster and support the development and implementation of high-quality EHRs in Europe and to offer related services to the industry, health professionals, and decision makers [24].

EuroRec takes on this task in different ways, e.g. by tutorials, scientific presentations, or networking. One way that is of major interest in this setting is their commitment to certification. 
Therefore, EuroRec aims at becoming the European Certification Body for Electronic Health Records.

\subsubsection{EuroRec Certification}

EuroRec has developed a repository of candidate certification criteria from the existing literature, such as norms or best practice as well as a basic set of tools to support quality certification, called Use-Tools. Access to the repository and criteria is open to the public. The criteria contained can be divided into Fine Grained Statements and Good Practice Requirements. Fine Grained Statements are basic, prime statements that can directly be referred to the sources. Good Practice Requirements are in general composed from one or more Fine Grained Statements and represent self-contained entities with regard to a specific topic/content. See $>$ table 2 for an example of the criteria.

All of the statements contained in the repository are categorized by different indices, including multiple indexing of single statements to increase the likelihood of finding relevant statements in a certain context. EuroRec differentiates three different types of indices: business functions, care settings, and component types. Each type of index contains a different number of subcategories and entries (Business functions: 50 entries, 8 subcategories; Care settings: 18 entries, 3 subcategories; Component types: 18 entries, 4 subcategories). The statements in the repository are available in more than 12 languages. The repository currently contains 1,612 Fine Grained Statements and 178 Good Practice Statements [25]. The process of extracting and adding statements to the EuroRecRepository is described in figure 1. Individual statements are taken in their original language in the source documents. These statements are translated into English and added to the Repository with a unique reference. Newly added and referenced statements are further broken down and indexed; the resulting statements are called Fine Grained Statements. Fine Grained Statements are in the next step composed into coherent Good Practice Statements, which are the basis for the certification of EHR Systems. In the next step, Good Practice Statements are selected and composed into profiles. According to each Good Practice Statement within a profile, the test criteria are defined. Profiles together with the test criteria are the basis for a specific EuroRec seal.

Out of the repository EuroRec has composed a set of basic, mainly functional criteria and put them together in quality seals. EuroRec offers two seals so far, the EuroRec 2008-2009 and the EuroRec 2010-2011 seal. Each seal comprises a certain amount of basic criteria that have to be fulfilled. The 2008-2009 seal comprises 20 criteria, whereas the 2010-2011 seal comprises 54 criteria [25].

\subsubsection{Cooperation and additional projects}

EuroRec is also in close cooperation with other organizations to reach its goals, among them the European Federation for Medical Informatics (EFMI), the International Standards Organization (ISO), the Comité Européen de Normalisation (CEN), the Certification Commission for Healthcare Information Technology (CCHIT), and the Healthcare Information and Management Systems Society (HIMSS). This cooperation is mainly focused on the exchange of requirements in order to match the different approaches to quality.

Apart from cooperation, EuroRec is involved in different projects on a European level. By the end of 2009, EuroRec was involved in and/or led the EHR-Q ${ }^{\text {tn }}$ project [27], the EHR Implement project [28], and the HITCH project. EHR-Q ${ }^{\text {tn }}$ is a thematic network project within the CIP-ICT PSP program that aims to increase awareness throughout Europe for the systematic and comparable quality certification of EHR systems, respectively eHealth systems, by elaborating the basis for quality certification including process definition, requirements etc. EHR-Implement collects, analyzes, and compares EHR implementations throughout Europe in order to provide best practice, policy, and strategic recommendations to foster the implementation of EHRs on a broad basis in Europe. The HITCH project within the seventh framework program establishes a roadmap to establish the basis for the conformance testing of the interoperability of healthcare information systems. This will be carried out by evaluating the existing approaches, identifying gaps, and proposing an achievable testing solution that can be implemented in the next five years. 


\subsection{Additional Quality Approaches}

Two certification approaches have been introduced so far. There are a number of other approaches that are of relevance in this context but that cannot be directly related to quality certification. The most prominent are the approaches from Integrating the Healthcare Enterprise (IHE) and openEHR, which is closely related to the EN/ISO 13606. Apart from those, there is a great number of Norms, Standards, Rule Sets, and other approaches that can be related to quality with regard to Electronic Health Records. As the number of available approaches is great, and their relevance often very limited or specific to a certain EHR domain or geographical region, they are not described in the present paper. For example, the approach from NEHTA (National e-Health Transition Authority, Australia) [29] - which defines an interoperability framework [30] - or MedCom (Denmark) [31] - which aims at certifying EDI/XML messages - are not described. In addition, basic standards such as HL7 messaging [32], Clinical Document Architecture (CDA) [33], DICOM [34], or terminologies, e.g. LOINC [35] and SNOMED CT [36] are also not in the scope of the present paper. However, there are indeed many sources available that provide an overview of such approaches or basic standards, see e.g. [13, 37-42].

\subsubsection{Integrating the Healthcare Enterprise}

Integrating the Healthcare Enterprise (IHE) [43] is an international organization that aims at achieving interoperability between different information systems in healthcare by defining the communication interfaces. IHE is driven by the strong cooperation of industry and scientific organizations. Therefore, IHE defines its mission as follows, "The goal of IHE is to improve the ability of computer systems in healthcare to share information so that all information relevant to a patient's care is available to the patient and the care provider when required." [44]. IHE is organized in many different national organizations that contribute to this mission on a regional basis and by the provision of input to the standardization efforts of IHE in different committees. In general the work of IHE can be separated into three levels; first by providing precise definitions of tasks in healthcare, second by specifying communication between systems with regard to specific tasks, based on existing standards and third by standardized the interoperability testing of systems.

These efforts are organized in different clinical and organizational domains. Currently, there are 10 domains in which IHE is involved: Anatomic Pathology, Cardiology, Eye Care, IT Infrastructure, Laboratory, Patient Care Coordination, Patient Care Devices, Quality, Research and Public Health, Radiation Oncology, and Radiology. In correspondence to each domain, IHE maintains technical frameworks that contain all of the relevant information with regard to a specific domain. The most important part of the technical frameworks is the integration profiles. These profiles summarize domain specific use cases and communication scenarios based on standards, in turn aiming at the provision of certain functionality, e.g. the Cross Enterprise Document Sharing (XDS) profile that defines the functionality for the registration and sharing of Electronic Health Record documents between different healthcare providers.

Information systems that implement one or more of the proposed integration profiles are eligible to participate in the annually organized IHE Connectathons where system interoperability is tested on a standardized basis. All of the systems that pass the testing are issued an IHE integration statement stating the profiles that have been tested successfully.

\subsection{2 openEHR}

The openEHR foundation [45] (successor of the Good European Health Record (GEHR) project) is a Non-profit organization that aims at implementing a life-long and interoperable Electronic Health Record to improve healthcare. It issues an open specification for a comprehensive and interoperable computing platform for EHR systems [46]. The specification was primarily developed from the experiences gained in the GEHR-project and can, therefore, be described as a best practice approach. Similar to the IHE-approach, openEHR does not define standards but rather uses the existing standards to provide certain EHR functionality. The specification of openEHR is based on an archetype concept that was inspired by the GEHR-project. The archetype concept derives information classes for a specific domain from a generic but health-specific reference-informationmodel, e.g. the generic class "Observation" is implemented as "Blood pressure" [47]. A major ad- 
vantage of the archetype concept is the separation of the relatively static information-layer from the dynamic, permanently changing knowledge-layer. Archetypes that are used by openEHR can be best compared to CDA Version 2 Templates [33] or DICOM Structured Reporting Templates [34]. Therefore, the openEHR specification not only provides functional but also, to a certain extent, semantic interoperability.

\subsubsection{EN 13606}

The first part of the four-part 13606 pre-standard was published in 1999. The other parts followed by the end of 2000 . The first implementations of the standard primarily did not succeed, as it used HL7 Version 2 for communication [46]. Due to the large amount of optional fields and values in the HL7 messaging, it was nearly impossible to guarantee interoperability without a clear agreement on how communication is to be implemented in detail between systems.

The CEN revised the standard in 2002 and committed to fundamental changes by adopting parts of the openEHR project, namely the archetype-approach and parts of the reference model [48]. The current version of the EN 13606 consists of five parts [41]: the Reference Model (EN 13606-1), the Archetype Interchange Specification (EN 13606-2), the Reference Archetypes and Term Lists (EN 13606-3), Security (EN 13606-4) and Exchange Models (EN 13606-5). The first four parts of the standard have been adopted by ISO as international standards to date.

As stated earlier, EN 13606 is in close relationship with the openEHR specification. $>$ Figure 2 shows the relationship between openEHR, EN 13606, and HL7.

\section{Discussion and Conclusion}

The certification of quality will play an important role in promoting the adoption of Electronic Health Records. System suppliers as well as purchasers can be provided with a clear definition on the system's requirements and capabilities [49]. This becomes especially important when smaller or local vendors access the market and EHRs are implemented on a broad basis. It is crucial to guarantee a minimum level of quality covering, among others, the security, functionality, and interoperability of the systems.

When faced with the decision to adopt new information technology and systems, purchasers often fear investment risks and tend to retain the existing solutions [50]. The certification of EHR systems addresses this problem in different ways. It provides purchasers with a basic quality guarantee and, therefore, also lays the foundation to claim a certain level of quality that is even more important when it comes to investing in new technologies or when systems do not meet customers' needs (see e.g. [51]).

Certification also increases transparency with regard to the comparison of different products and fosters buyers' knowledge about the products, as certification organizations often compile information about different products and technologies [42]. Increased transparency and knowledge in turn have a positive impact on the buyers' willingness to invest in new technology.

Apart from the advantages for health care providers and suppliers, certification offers possibilities for public bodies to influence the adoption of high quality EHRs by offering (financial) incentives for the selection of certified systems. Such a system is currently being implemented in the US in the context of the American Recovery and Reinvestment Act of 2009 [18], as described hereinabove.

Nationwide or even worldwide certification criteria and/or approaches also allow for a concentration of efforts. Vendors, purchasers, and payers are provided with a hub to introduce their needs and requirements. Small health care providers, professional associations, or even single physician offices gain the possibility to actively influence the market.

But it is indeed unclear which measurable impact is actually caused by certifications on the quality of EHRs. There is a lack of studies which evaluate and measure - based on a sound methodological approach - the increase in quality. Based on the experiences from other domains such as the business domain it seems that certification increases quality (see e.g. [52]) but is only one element within a holistic approach to increase and support quality. In addition, the positive or negative 
effects of current and future quality certification approaches heavily depend on their specific ability to at least embrace the above mentioned potentials. The actual design of a certification approach with its content, structure, certification processes, transparency, relevance, and suitability account for its utility [53]. A good example in this context is the Connectathon that is organized by IHE. In order to be eligible for a certain profile, systems have to prove that they are able to communicate with three other systems by using the corresponding profile. If a system manages to communicate with three different systems but fails to communicate with a series of other systems, it is still eligible for that profile [54]. In general, IHE contributes heavily via their work to increase the quality of EHRs, but the Connectathon leaves some room for questions.

Therefore, the next section will summarize and contrast the approaches described with regard to their content and structure, relevance, and, if applicable, certification processes to allow an individual judgment of the approaches.

\subsection{Content and Structure}

As aforementioned, CCHIT primarily covers functional requirements and some security and interoperability requirements. Non-functional requirements are largely neglected in the CCHIT certification, which can be regarded as a deficit. With regard to the structure, the CCHIT approach is hierarchically structured and divided into criteria and sub-criteria. It implicitly assumes monolithic systems.

EuroRec pursues a broader approach; it is not limited to functional criteria, in which it also considers non-functional criteria. The criteria certified by EuroRec are also hierarchically structured and monolithic systems are assumed.

The requirements, respectively profiles, defined by the IHE in its different domains mainly cover interoperability with regard to specific functionality, such as the exchange of lab results, retrieval of ECG etc. The IT infrastructure domain also includes instructions - apart from interoperability concerns - that are relevant for system security. The approach of the IHE supports the use and implementation of service-oriented architectures, which is principally due to the encapsulation of different functional entities in the profiles. EN 13606 as well as openEHR offer a concept for the design of interoperable EHR systems, but they do not specify the requirements or profiles for different application domains as is carried out by the IHE. They also do not support service-orientation, which was also observed by Blobel [55].

A major problem of the approaches mentioned (except for IHE) is that they implicitly assume a monolithic system that is not true for most modern EHR-systems, which have a trans-institutional nature and are primarily composed of different, functional-independent, and distributed services. This has particular influence on the potential of certification approaches such as those from CCHIT and EuroRec in order to be able to certify future systems.

Another deficiency of the approaches is their lack of considering stakeholders other than health care providers. None of the approaches consider patients or similar groups.

None of the approaches is harmonized or interrelated with the others, although there is cooperation and an exchange of information between the different organizations. The recently initiated $\mathrm{HITCH}$ project is one effort being made towards changing this situation.

\subsection{Certification}

CCHIT has detailed process descriptions of the certification. The actual certification is based on a demonstration of predefined test scenarios by the system supplier. This clearly involves the risk that system suppliers will optimize their systems with regard to the test scenarios.

As the certification that is offered by EuroRec is still in its beginnings, there are no formal process specifications for the certification of systems. EuroRec is currently working on the specification of such processes in order to increase transparency and credibility. EuroRec, so far, is also not distinguishing different EHR-systems. There is only one certification for all systems. In addition, the number of criteria being certified is small; this is especially true for their 2008/2009 certificate.

The IHE organizes Connectathons every year in order to have systems certified according to their profiles, although they do not call it 'certification', as there is no formal audit. One of the ma- 
jor problems of the IHE approach is that there are no formal processes defined when profiles become invalid, e.g. annual recertification. This results in the situation that system providers can change their systems after a Connectathon and still keep the same integration statement. Another problem that was already introduced is insufficient regulations for testing. This leaves room for system providers to bypass thorough testing.

There are, so far, no certifications or similar process in order to certify a system according to openEHR or EN 13606.

\subsection{Relevance and geographical extension}

CCHIT is predominantly relevant in the US and is accredited by the Federal Government as a Certification Body and can, therefore, be regarded as the leading certification organization within the US. Outside the US, CCHIT is not yet certifying systems. The same is true for EuroRec with the sole difference that EuroRec is focused on the European Union and does not operate outside of Europe.

IHE is not limited to certain countries and is widely accepted within the system suppliers' community. This may be traced back to the fact that IHE was initiated mainly as an industry initiative. As IHE has its origin in the US, the distribution and use of IHE profiles is by trend higher than in Europe or Asia. However, the use of IHE in Europe has significantly increased in recent years.

OpenEHR, respectively EN13606, have their roots in Europe and, therefore, have a stronger influence on system development within Europe. Through the fact that the openEHR project was moved to Australia in 1996, it also has a strong influence there.

What can be observed is that openEHR/EN13606 and IHE are not necessarily seen as competitors as they serve different needs. IHE provides system suppliers with a feasible concept for realizing inter-organizational, technical system interoperability, whereas openEHR/EN13606 with its archetype concept supports the modeling of clinical information better.

This review summarizes and discusses major approaches that support or certify the quality of EHRs that are freely available, mainly EHR-specific and of transnational interest. The review does not introduce approaches that are in a development state, merely scientific, general, or on a national or regional level.

Although we have tried to include all the relevant sources in our analysis, we might have missed some relevant publications. Our review was focused on quality certification, although the search criteria were designed for a broader fit of the topic. Therefore, approaches that are not labeled as certifications might have also been missed. It seems that only European, US, and Australian approaches have been introduced but by the time of writing no Asian approaches or approaches from elsewhere were known to the authors.

\section{Practical Implications of the Results}

The available certification approaches as well as the approaches that foster the quality and interoperability of systems as described in the present paper should be used by system vendors as a source for the improvement of their products. They also provide a solid basis for interoperability, especially the requirements that are defined by IHE. System vendors should start to get their products certified where applicable or at least use them for the internal evaluation of their systems.

Users as well as organizations in the healthcare sector should also make use of the existing quality approaches. This should be done, not only by selecting systems based on their certification, but also by using the knowledge and information that are contained in these approaches. The approaches may, for example, be used to benchmark the existing systems or on a strategic level to support the development of IT strategies.

On the other hand, it is important to state that the currently available certification approaches are not sufficient to guarantee high quality systems or system interoperability. They should be regarded as important basic quality indicators that support comprehensive efforts to implement high quality systems.

\section{Conflict of Interest}

Alexander Hoerbst is the Head of ProRec in Austria, which is a part of EuroRec. 


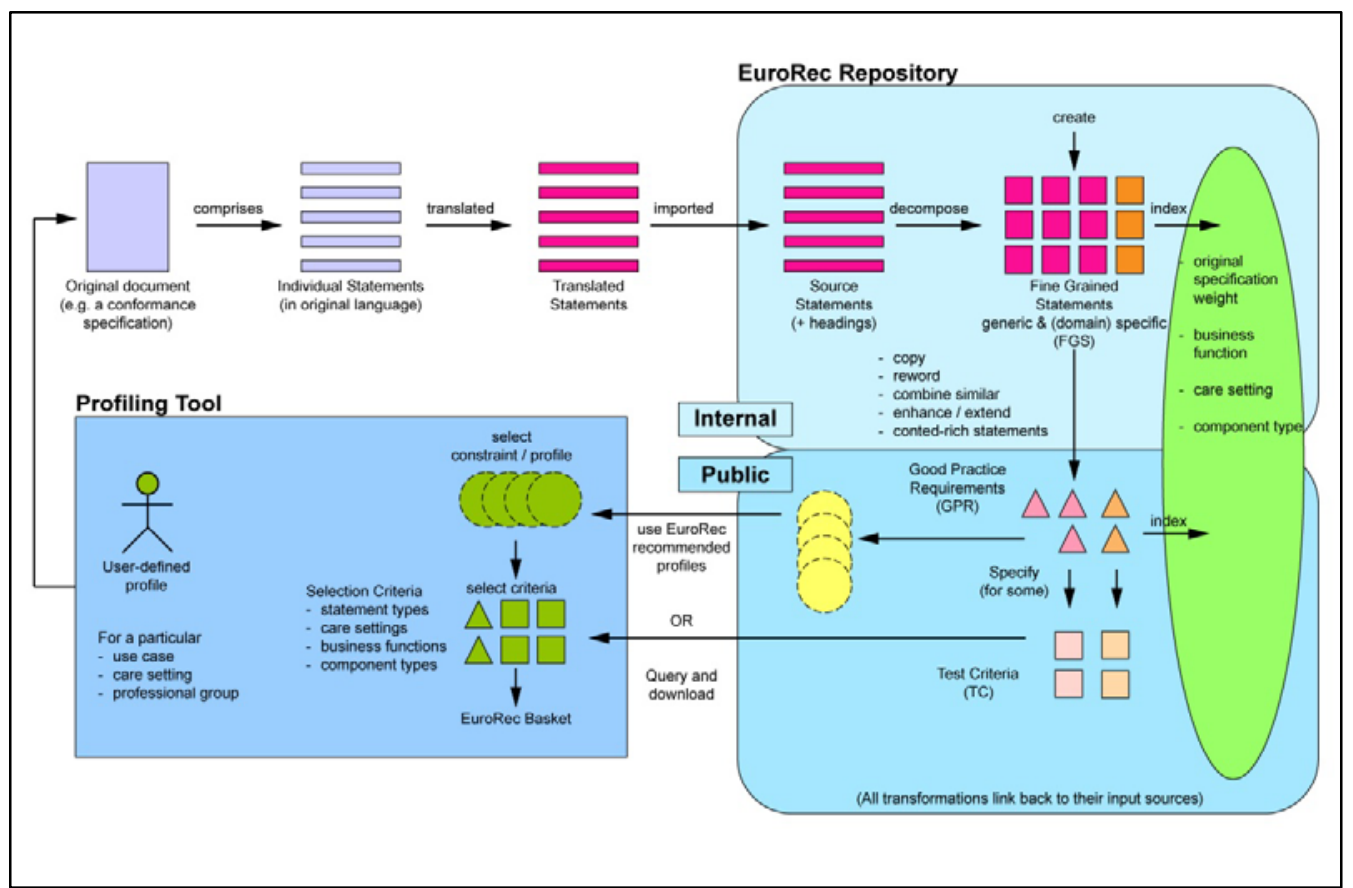

Fig. 1 EuroRec requirements lifecycle [26] (Figure by courtesy of Jos Devlies)

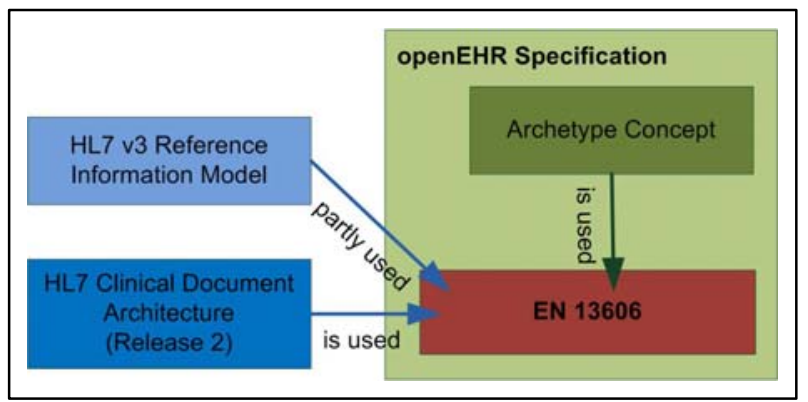

Fig. 2 Relationship between EN 13606, openEHR, and HL7 (based on [46]) 
Table 1 Functional criteria CCHIT - examples

\begin{tabular}{l|l}
$\begin{array}{l}\text { Categories } \\
\text { Support for drug }\end{array}$ & $\begin{array}{l}\text { Criteria } \\
\text { interaction } \\
\text { been noted to be ineffective for the patient in the past, and alert the user at the time of } \\
\text { medication ordering if noted ineffectiveness exists. }\end{array}$ \\
\hline $\begin{array}{l}\text { Order medication } \\
\text { The system shall provide the ability to capture common content for prescription details } \\
\text { including strength, sig, quantity, and refills to be selected by the ordering clinician. }\end{array}$ \\
\hline $\begin{array}{l}\text { Manage allergy and } \\
\text { adverse reaction list }\end{array}$ & $\begin{array}{l}\text { The system shall provide the ability to specify the type of allergic or adverse reaction in a } \\
\text { discrete data field. }\end{array}$ \\
\hline $\begin{array}{l}\text { Manage } \\
\text { medication list }\end{array}$ & $\begin{array}{l}\text { The system shall provide the ability to enter or further specify in a discrete field that the } \\
\text { patient takes no medications. }\end{array}$
\end{tabular}

Table 2 EuroRec Good Practice Statements with corresponding Fine Grained Statements - example

\begin{tabular}{|c|c|}
\hline jooc & tts \\
\hline \multirow{4}{*}{$\begin{array}{l}\text { EHR access is only allowed after the user has } \\
\text { authenticated himself as defined in the informa- } \\
\text { tion security policy. Only those parts of the EHR } \\
\text { are accessible for which the user has sufficient } \\
\text { authorization. Authorization is based upon his role } \\
\text { in the care setting and upon individual authoriza- } \\
\text { tions granted or revoked in relations to specific } \\
\text { parts of the EHR. Authorization can be further } \\
\text { modified by parameters such as time or location of } \\
\text { access. }\end{array}$} & \\
\hline & of \\
\hline & e \\
\hline & $\begin{array}{l}\text { The system enables the author of a version of a health item to } \\
\text { assign a level of access. }\end{array}$ \\
\hline
\end{tabular}


Table 3 Summary of the main attributes for the approaches introduced

\begin{tabular}{|c|c|c|c|c|c|c|c|c|c|}
\hline Approach & Focus & $\begin{array}{l}\text { Service- } \\
\text { Orienta- } \\
\text { tion }\end{array}$ & $\begin{array}{l}\text { Certification/ } \\
\text { Testing }\end{array}$ & $\begin{array}{l}\text { Re-Certi- } \\
\text { fication }\end{array}$ & $\begin{array}{l}\text { No. of Sys- } \\
\text { tems certi- } \\
\text { fied/tested }\end{array}$ & Relevance & Foundation & Origin & Link \\
\hline CCHIT & $\begin{array}{l}\text { Mainly functional re- } \\
\text { quirements including } \\
\text { some requirements for } \\
\text { interoperability and } \\
\text { security }\end{array}$ & No & $\begin{array}{l}\text { System demonstration } \\
\text { based on test scenar- } \\
\text { ios }\end{array}$ & $\begin{array}{l}\text { Annually or } \\
\text { after major } \\
\text { changes }\end{array}$ & $\begin{array}{l}210 \text { by the end } \\
\text { of } 2009\end{array}$ & $\begin{array}{l}\text { Mainly in } \\
\text { the US }\end{array}$ & $\begin{array}{l}\text { Founded 2004; } \\
\text { Certification since } \\
2006\end{array}$ & $\begin{array}{l}\text { In the US by } \\
\text { AHIMA, HIMSS } \\
\text { and Alliance }\end{array}$ & www.cchit.org \\
\hline EuroRec & $\begin{array}{l}\text { Functional and non- } \\
\text { functional requirements }\end{array}$ & No & $\begin{array}{l}\text { So far no detailed } \\
\text { testing processes } \\
\text { implemented }\end{array}$ & $\begin{array}{l}\text { Seal has } \\
\text { validity } \\
\text { (normal } 2 \\
\text { years) }\end{array}$ & $\begin{array}{l}<10 \text { by the end } \\
\text { of } 2009\end{array}$ & $\begin{array}{l}\text { European } \\
\text { Union }\end{array}$ & $\begin{array}{l}\text { Prorec Initiative } \\
\text { started 1996; } \\
\text { Certification since } \\
2008\end{array}$ & $\begin{array}{l}\text { In Europe by the } \\
\text { concerted MEDI- } \\
\text { REC action of the } \\
\text { EU }\end{array}$ & www.eurorec.org \\
\hline IHE & Interoperability & Yes & $\begin{array}{l}\text { Connectathon; systems } \\
\text { have to prove interop- } \\
\text { erability for a certain } \\
\text { profile with at least } 3 \\
\text { other systems }\end{array}$ & $\begin{array}{l}\text { After major } \\
\text { changes }\end{array}$ & $\begin{array}{l}\text { Connectathon } \\
2009 \\
\text { Europe: } 61 \\
\text { North America: } \\
67\end{array}$ & Worldwide & $\begin{array}{l}\text { Founded 1997; } \\
\text { First profile (Radi- } \\
\text { ology) } 1999\end{array}$ & $\begin{array}{l}\text { In the US by RSNA } \\
\text { and HIMSS }\end{array}$ & www.ihe.net \\
\hline $\begin{array}{l}\text { openEHR/ } \\
\text { EN13606 }\end{array}$ & $\begin{array}{l}\text { Functional and non- } \\
\text { functional requirements; } \\
\text { complete EHR }\end{array}$ & No & $\begin{array}{l}\text { No testing or certifica- } \\
\text { tion }\end{array}$ & $\begin{array}{l}\text { Nonapplica- } \\
\text { ble }\end{array}$ & Nonapplicable & Worldwide & $\begin{array}{l}\text { Known as } \\
\text { openEHR since } \\
1999\end{array}$ & $\begin{array}{l}\text { In Europe from the } \\
\text { GEHR and SYNAP- } \\
\text { SIS project }\end{array}$ & www.openehr.org \\
\hline \multicolumn{10}{|c|}{$\begin{array}{l}\text { Service-Orientation: The category service-orientation indicates if an approach easily supports the certification/implementation of service-oriented architectures for EHRs. This is regarded as } \\
\text { the opposite of monolithic systems in this special context. }\end{array}$} \\
\hline \multicolumn{4}{|c|}{ AHIMA: American Health Information Management Association } & \multicolumn{6}{|c|}{ HIMSS: Health Information and Management Systems Society } \\
\hline \multicolumn{4}{|c|}{ Alliance. National Alliance for Health Information Technology } & \multicolumn{6}{|c|}{ RSNA: Radiological Society of North America } \\
\hline
\end{tabular}




\section{References}

1. Berner E, Moss J. Informatics challenges for the impending patient information explosion. J Am Med Inform Assoc 2005; 12(6): 614-617.

2. Eurostat. Database Query - Healthcare Expenditures for all healthcare providers, per inhabitant from 2003 to 2006. http://epp.eurostat.ec.europa.eu/portal/page/portal/health/public_health/database

3. Burns F. Information for Health: An information strategy for the modern NHS 1998-2005. A national strategy for local implementation. 2006 [cited 2010 10.01.]; Available from: http://www.dh.gov.uk/en/Publicationsandstatistics/Publications/PublicationsPolicyAndGuidance/DH_40 02944

4. Sittig DF. Personal health records on the internet: a snapshot of the pioneers at the end of the 20th Century. Int J Med Inform 2002; 65(1): 1-6.

5. Detmer D, Bloomrosen M, Raymond B, Tang P. Integrated personal health records: transformative tools for consumer-centric care. BMC Med Inform Decis Mak 2008; 8: 45.

6. Waegemann C. Testimony Regarding Personal Health Records. National Committee on Vital and Health Statistics. Chicago, IL, July 24, 2002. 2002 [cited 2010 10.01.]; Available from: http://www.ncvhs.hhs.gov/020724p6.htm.

7. National IT Strategy 2003-2007 for the Danish Health Care Service, Ministry of the Interior and Health, Editor. 2003, Ministry of the Interior and Health.

8. Bernstein K et al. Modelling and implementing electronic health records in Denmark. Methods of Information in Medicine, 2005; 74(2): 213-220.

9. Hörbst A, Schabetsberger T, Ammenwerth E. Die Elektronische Gesundheitsakte - Interesse und Akzeptanz der Tiroler Bürger in eHealth2008 - Medical Informatics meets eHealth: Tagungsband eHealth2008 \& eHealth Benchmarking 2008. Wien: OCG.

10. ISO 9000, ISO 9000 - Quality management systems. Fundamentals and vocabulary. 2005, International Organization for Standardization.

11. CCHIT. About the Certification Commission for Health Information Technology. [Website] 2009 [cited 2010 10.01.]; Available from: http://www.cchit.org/about.

12. Leavitt M, O'Kane ME. Joint Statement from the National Committee for Quality Assurance and the Certification Commission for Healthcare Information Technology. 2005 [cited 2009 10.12.]; Available from: http://www.ncqa.org/Portals/0/Newsroom/2005/Joint_5_24_05.pdf.

13. Hörbst A. Grundlagen der Qualitätszertifizierung von Diensten im Rahmen der Elektronischen Gesundheitsakte, in Institute for Health Information Systems. 2008, UMIT - University for Health Sciences, Medical Informatics and Technology: Hall in Tyrol. p. 321.

14. CCHIT. Get involved with the Certification Commission. 2009. [cited 2010 10.01.]; Available from: http://www.cchit.org/participate

15. CCHIT. Certification Handbook: CCHIT Certified 2011 - Comprehensive Certification Program 2009 [cited 2010 10.01.]; Available from: http://www.cchit.org/sites/all/files/CCHIT\%20Certified\%202011\%20Comprehensive\%20Certification\%2 0Handbook\%20Oct\%2020\%202009.pdf.

16. NCQA. NCQA to Certify Electronic Health Record (EHR) Systems; Certification Based on Compatibility with Diabetes Program. National Committee for Quality Assurance; 2005 [cited 2010 10.01.]; Available from: http://www.ncqa.org/tabid/281/Default.aspx.

17. CCHIT. Project Laika. Certification Commission for Health Information Technology. 2009 [cited 2010 10.01.]; Available from: http://www.cchit.org/laika.

18. Public Law 111-5. American Recovery and Reinvestment Act of 2009. 2009. [cited 2010 10.01.]; Available from: http://www.gpo.gov/fdsys/pkg/PLAW-111publ5/pdf/PLAW-111publ5.pdf

19. Office of the National Coordinator for Health Information Technology. Federal Advisory Committees. 2009. [cited 2010 10.01.]; Available from: http://healthit.hhs.gov/portal/server.pt?open=512\&objID=1149\&parentname=CommunityPage\&parenti $\mathrm{d}=40$ \&mode $=2 \&$ in_hi_userid $=10741$ \&cached $=$ true

20. Health IT Policy Committee. Health IT Policy Council Recommendations to National Coordinator for Defining Meaningful Use. 2009. [cited 2010 10.01.]; Available from: http://healthit.hhs.gov/portal/server.pt/gateway/PTARGS_0_10741_888532_0_0_18/FINAL\%20MU\%20 RECOMMENDATIONS\%20TABLE.pdf

21. HIT Standards Committee - Joint Working Groups on Quality and Operations. Meaningful Use Measure Grid - Data Elements Mapped to HITEP Datatypes. 2009. [cited 2010 10.01.]; Available from: http://healthit.hhs.gov/portal/server.pt/gateway/PTARGS_0_11113_880493_0_0_18/MU\%20Grid\%20Dat a\%20Element\%20Standards_08202009.pdf 
22. HIT Standards Committee. PRIVACY AND SECURITY STANDARDS APPLICABLE TO ARRA REQUIREMENTS. 2009. [cited 2009 10.12.]; Available from:

http://healthit.hhs.gov/portal/server.pt/gateway/PTARGS_0_11113_880497_0_0_18/PRIVACY\%20AND \%20SECURITY\%20STANDARDS\%20APPLICABLE\%20TO\%20ARRA\%20REQUIREMENTS.pdf

23. CCHIT. Certification Handbook - Preliminary ARRA 2011 Certification Program. 2009. [cited 2010 10.01.]; Available from: http://www.cchit.org/sites/all/files/Preliminary\%20ARRA\%202011\%20Certification\%20Handbook\%20O ct\%2020\%202009.pdf

24. EuroRec. Articles of Association. 2009 01.11. [cited 2010 10.01.]; Available from: http://www.eurorec.org/files/filesPublic/Articles\%20of\%20Association\%20November\%202009.pdf

25. Devlies J. The EuroRec Seal 2010. 2009 [cited 2010 10.01.]; Available from: http://www.eurorec.org/files/filesPublic/eurorec2009/Seal2010Sarajevo.ppt

26. de Moor G. Extending "Certification of Electronic Health Records" at a Pan-European Level. 2009. [cited 2010 10.01.]; Available from: http://www.eurorec.org/files/filesPublic/Prague\%2019feb09\%20\%20DE\%20MOOR\%20Certification_alt.zip

27. European Commission. EHR-Q-TN: Thematic Network on Quality and Certification of EHR systems. 2009 [cited 2010 10.01.]; Available from: http://ec.europa.eu/information_society/apps/projects/factsheet/index.cfm?project_ref=238912.

28. Esterle L. EHR-Implement - National policies for EHR implementation in the European area: social and organizational issues. 2009 [cited 2010 10.01.]; Available from: http://www.ehr-implement.eu/.

29. National E-Health Transition Authority (NEHTA). The National E-Health Transition Authority Strategic Plan (2009-2012). 2009 [cited 2010 10.01.]; Available from: http://www.nehta.gov.au/about-us/strategy.

30. National E-Health Transition Authority (NEHTA). Interoperability Framework Version 2.0. 2007 [cited 2010 10.01.]; Available from: http://www.nehta.gov.au/component/docman/doc_details/391interoperability-framework-v20.

31. MedCom. MedCom - in English. 2009 [cited 2010 10.01.]; Available from: http://www.medcom.dk/wm109991.

32. Health Level 7. V3 Messaging Standard. 2009 [cited 2010 10.01.]; Available from: http://www.hl7.org/implement/standards/v3messages.cfm.

33. Health Level 7. Clinical Document Architecture. 2009 [cited 2010 10.01.]; Available from: http://www.hl7.org/implement/standards/cda.cfm.

34. National Electrical Manufacturers Association. DICOM - Strategic Document. 2009 [cited 2010 10.01.]; Available from: http://medical.nema.org/dicom/geninfo/Strategy.pdf.

35. McDonald C, Huff S, Mercer K, Hernandez J, Vreeman D. Logical Observation Identifiers Names and Codes $\left(\right.$ LOINC $^{\circledR}$ ) Users' Guide. 2009 [cited 2010 10.01.]; Available from: http://loinc.org/downloads/files/LOINCManual.pdf.

36. International Health Terminology Standards Development Organization. About Snomed CT. 2009 [cited 2010 10.01.]; http://www.ihtsdo.org/snomed-ct/snomed-ct0/

37. Blobel B. Q-Rec Project - Inventory of Relevant Standards for EHR Systems. 2007 [cited 2010 10.01.]; Available from: http://www.eurorec.org/services/standards/Q-RECEurorec_Overview\%20on\%20EHR\%20Standards\%2001.pdf

38. National E-Health Transition Authority (NEHTA). Review of Shared Electronic Health Record Standards. Sydney, Australia: National E-Health Transition Authority; 2006 [cited 2010 10.01.]; Available from: http://www.nehta.gov.au/component/docman/doc_download/68-review-of-shared-electronichealth-records-standards-v10

39. Eichelberg M, Aden T, Riesmeier J, Dogac A, Laleci GB. Electronic Health Records Standards - a Brief Overview. In: Proceedings of the 4th IEEE International Conference on Information and Communications Technology (ICICT 2006). 2006.

40. Eysenbach G, Powell J, Kuss O, Sa E-R. Empirical studies assessing the quality of health information for consumers on the World Wide Web: a systematic review. Journal of the American Medical Association 2002; 287(20): 2691-2700.

41. Kalra D. Electronic Health Record Standards. IMIA Yearbook of Medical Informatics 2006. Stuttgart: Schattauer GmbH, 2006; 136-144.

42. Ludwick D, Doucette J. A Review of General Practice System Certification Programs in Seven Countries and five Canadian Provinces. Healthcare Quarterly 2009; 12(3): 111-123.

43. IHE International. About IHE. 2009 [cited 2010 10.01.]; Available from: http://www.ihe.net/About/.

44. IHE International. Integrating the Healthcare Enterprise (IHE) International - Principles of Governance. 2007. Available from: http://www.ihe.net/governance/upload/IHE_Governance_Interim_Document_2007_10_05.pdf. 
45. openEHR. The openEHR Foundation. 2008 [cited 2010 10.01.]; Available from: http://www.openehr.org/about/foundation.html

46. Schloeffel P, Beale T, Hayworth G, Heard S, Leslie H. The Relationship between CEN 13606, HL7, and OpenEHR. In: HIC 2006 and HINZ 2006: Proceedings. Westbrook J, Callen J, Margelis G, Warren J (Editors). Brunswick East, Vic.: Health Informatics Society of Australia, 2006.

47. Eichelberg M, Aden T, Riesmeier J, Dogac A, Laleci BG. A Survey and Analysis of Electronic Healthcare Record Standards. ACM Computing Surveys 2005; 37(4): 277-315.

48. Bergmann J. openEHR - Die Geschichte eines Baukastensystems für eine gemeinsame Elektronische Gesundheitsakte. Forum der Medizin Dokumentation und Medizin Informatik 2005; 1: 8-15.

49. Classen D, Avery A, Bates D. Evaluation and Certification of Computerized Provider Order Entry Systems. Journal of the American Medical Informatics Association. 2007; 14(1): 48-55.

50. Ludwick DA, Doucette J. Adopting Electronic Medical Records in Primary Care: Lessons Learned from Health Information Systems Implementation Experience in Seven Countries. International Journal of Medical Informatics. 2009; 78(1): 22-31.

51. Han Y, Carcillo J, Venkataraman S, Clark R, Watson S, Nguyen T, Bayir H, Orr R. Unexpected increased mortality after implementation of a commercially sold computerized physician order entry system. Pediatrics. 2005; 116: 1506-1512.

52. Terlaak A, King AA. The effect of certification with the ISO 9000 Quality Management Standard: A signaling approach. Journal of Economic Behavior \& Organization 2006; 60(4): 579-602.

53. Hoerbst A, Schabetsberger T, Hackl W, Ammenwerth E. Requirements Regarding Quality Certification of Electronic Health Records. In: Adlassnig K.-P, Blobel B, Mantas J, Masic I (Eds.): Medical Informatics in a United and Healthy Europe - Proceedings of MIE 2009 - The XXIInd International Congress of the European Federation for Medical Informatics. Studies in Health Technology and Informatics Vol. 150. Amsterdam: IOS Press.

54. Integrating the Healthcare Enterprise (IHE) International. IHE 2010 North America Connectathon Policies and Guidelines. 2009. Available from: http://www.ihe.net/north_america/upload/NA2010Connectathon-Policies-and-Guidelines_2009-08-27.pdf.

55. Blobel, Bernd und Pharow, Peter (2008) Analysis and Evaluation of EHR Approaches. In: Andersen, Stig Kjær und Klein, G.O. und Schulz, S. und Arts, J. und Mazzoleni, M.C ., (eds.) eHealth beyond the horizon - get IT there: proceedings of MIE 2008, the XXIst international congress of the European Federation for Medical Informatics. Studies in health technology and informatics, 136. IOS Press, Amsterdam, S. 359364. 